\title{
INFLUENCE OF OXYGEN ADDITION ON THE STRUCTURAL AND ELASTIC PROPERTIES OF TiC THIN FILMS
}

\author{
*Luís S. A. Marques, Ana. C. Fernandes, Filipe Vaz, Marta M. D. Ramos \\ Universidade do Minho, Departamento de Física, Campus de Gualtar, 4710-057, Braga, Portugal
}

\section{Full Mailing Address:}
Luís S. A. Marques
Universidade do Minho
Departamento de Física
Campus de Gualtar
4710-057 Braga
Portugal

Fax:

$+351-253604061$

\section{E-mail:}

1sam@fisica.uminho.pt 


\title{
Keywords
}

Density functional theory (DFT), titanium oxycarbide; structure; elastic constants, thin films

\begin{abstract}
We have studied the structural, electronic and mechanical properties of $\mathrm{TiC}_{\mathrm{x}} \mathrm{O}_{\mathrm{y}}$, using first principles calculations based on the density functional theory and pseudopotential method, within the generalized gradient approximation for the exchange-correlation functional. These calculations provide the lattice parameter, density of states, cohesive energy, elastic constants and moduli as a function of carbon and oxygen content. The calculated values of lattice parameters and elastic moduli are generally in good agreement with experiments and compare well with other theoretical results.
\end{abstract}




\section{Introduction}

Transition metal compounds, such as $\mathrm{TiC}$ and $\mathrm{TiO}$, belong to the class of refractory metal compounds. In stoichiometric condition they exhibit a cubic B1 type structure, but commonly produced films are substoichiometric with vacancies on both metal and non-metal sublattices. They can show metallic as well as covalent and ionic properties, exhibiting a unique combination of characteristics that allow them to be serious candidates for a wide range of high-technology applications in many fields, such as metallurgy, aeronautics, electronics and medicine ${ }^{[1-6]}$. However, most applications of the transition-metal carbides rely upon their extreme hardness and wear resistance, characteristic of covalent crystals, in order to decrease wear in a variety of components ${ }^{[1]}$. The pursue of new and multifunctional applications, have prompted many investigations on this kind of refractory compounds. In this respect, the addition of oxygen to the Ti-C matrix allows the tailoring of film properties between those of metal carbides, as the case of TiC, and those of the correspondent large ionic oxides, with the consequent wide variation in the materials properties.

In this work, ab initio density functional theory calculations were performed to investigate the effect of oxygen/carbon content on the structural, electronic and mechanical properties of $\mathrm{TiC}_{\mathrm{x}} \mathrm{O}_{\mathrm{y}}$ structures. The calculations provide insight into theoretical lattice parameter, density of states, cohesive energy, elastic constants and moduli as a function of carbon and oxygen content, which results are found generally in good agreement with experiments, performed by us and other research teams, as well as other theoretical calculations. To our knowledge, this is the first theoretical study of the mechanical properties of TiCO compounds.

\section{Computational method}

The first principles calculations were performed within the density functional theory ${ }^{[7]}$ (DFT) formalism, using the Cambridge Serial Total Energy Package (CASTEP) software ${ }^{[8]}$. The CASTEP software solves the Kohn-Sham equations with periodic boundary conditions and the 
pseudopotential method as an approximation of the atomic core - valence electron interaction, while the electronic wavefunctions are expanded in a plane wave basis. We adopted the norm conserving pseudopotentials provided within the package and the generalized gradient density approximation of Perdew, Burke and Ernzerhof (GGA-PBE) ${ }^{[9]}$ for the exchange-correlation functional. The Brillouin zone was sampled with the Monkhorst-Pack scheme ${ }^{[10]}$ using a k point separation of $0.04 \AA^{-1}$ in a 6x6x6 grid in reciprocal space. A plane wave energy cutoff of $660 \mathrm{eV}$ and an energy convergence limit of $5 \times 10^{-7} \mathrm{eV} /$ atom were used in total energy calculations, guaranteeing a high level of convergence.

An eight atom cubic unit cell model with rock salt structure was used to calculate the ground state energy, lattice parameter, density of states and elastic constants of $\mathrm{TiC}_{\mathrm{x}} \mathrm{O}_{\mathrm{y}}$ films. In order to study the effect of oxygen incorporation on the properties of $\mathrm{TiC}$, some carbon atoms in the initial $\mathrm{TiC}$ structure were replaced by oxygen atoms. The geometries of structures were fully optimized using the Broyden-Fletcher-Goldfarb-Shanno (BFGS) minimization technique with the following tolerances: energy changes less than $5 \times 10^{-6} \mathrm{eV} /$ atom, residual force is less than $10^{-2} \mathrm{eV} / \AA$, displacement of atoms is less than $5 \times 10^{-4} \AA$ and residual bulk stress is less than $2 \times 10^{-2} \mathrm{GPa}$.

The cohesive energy was calculated in the usual way from the difference in total energy between the isolated atoms and the $\mathrm{TiC}_{\mathrm{x}} \mathrm{O}_{\mathrm{y}}$ compound

$$
\mathrm{E}_{\mathrm{coh}}\left(\mathrm{TiC}_{\mathrm{x}} \mathrm{O}_{\mathrm{y}}\right)=\left[\mathrm{n}_{\mathrm{Ti}} \cdot \mathrm{E}_{\text {tot }}(\mathrm{Ti})+\mathrm{n}_{\mathrm{C}} \cdot \mathrm{E}_{\text {tot }}(\mathrm{C})+\mathrm{n}_{\mathrm{O}} \cdot \mathrm{E}_{\text {tot }}(\mathrm{O})\right]-\mathrm{E}_{\text {tot }}\left(\mathrm{TiC}_{\mathrm{x}} \mathrm{O}_{\mathrm{y}}\right)
$$

with $\mathrm{n}_{\mathrm{Ti}}, \mathrm{n}_{\mathrm{C}}, \mathrm{n}_{\mathrm{O}}$ being the number of titanium, carbon and oxygen atoms in the compound, respectively.

The shear modulus $(G)$, was obtained from the Bulk modulus $(B)$ and Young modulus $(E)$ values calculated by CASTEP, using the following equation

$$
E^{-1}=(3 G)^{-1}+(9 B)^{-1}
$$




\section{Experimental details}

In order to compare the calculated mechanical properties with experimental ones, $\mathrm{TiC}_{\mathrm{x}} \mathrm{O}_{\mathrm{y}}$ films were prepared by dc reactive magnetron sputtering from a TiC target, using a laboratory-size deposition system. A gas atmosphere composed of argon and oxygen was used. The structural features (crystalline phase and lattice parameters) were investigated by X-ray diffraction (XRD) in the Bragg-Bretano configuration, using monochromatic $\mathrm{Cu} \mathrm{K} \alpha$ radiation. The Young's modulus was determined from hardness experiments, carried out with an ultra low load-depth sensing Berkovich nanoindenter from CSM Instruments (Switzerland), using the loading and unloading curves,.

\section{Results and discussion}

Fig. 1 shows the density of states (DOS) for stoichiometric bulk TiC. This DOS has a low lying band at $-9.5 \mathrm{eV}$ due to $\mathrm{C} 2 \mathrm{~s}$ states, separated from the next feature by an energy gap of $4 \mathrm{eV}$. The next band structure is originated from the Ti $3 \mathrm{~d}$ orbitals of $\mathrm{e}_{\mathrm{g}}$ symmetry hybridizing with the non metal $\mathrm{C}$ $2 \mathrm{p}$ orbitals, indicating a strong interaction between $\mathrm{C} 2 \mathrm{p}$ and $\mathrm{Ti} 3 \mathrm{~d}$ electrons, and represents the main covalent bonding component. The corresponding antibonding states are found in the zone above the pseudogap. The metallic character of TiC is revealed from the nonzero DOS at the Fermi level.

Fig. 2 shows the DOS for stoichiometric bulk TiO. The band due to $\mathrm{O} 2 \mathrm{~s}$ states lies very far from the next band structure, made up essentially of $\mathrm{O} 2 \mathrm{p}$ bonding states, with an energy gap of $11 \mathrm{eV}$ between them. The Ti $3 \mathrm{~d}$ and $\mathrm{O} 2 \mathrm{p}$ bands are separated in energy by a gap of $2 \mathrm{eV}$, resulting in a very weak p-d hybridization in contrast with TiC. The Fermi level lies within a sharply increasing peak, essentially made up of Ti $3 d$ states, which means that the metallic bonding plays a major role in determining the properties of TiO. The cohesive energy, intrinsic hardness and bulk modulus are expected to be higher for $\mathrm{TiC}$ than for $\mathrm{TiO}$ due to the more covalent nature of bonds, as a result of the strong hybridization. These results are consistent with previous calculations for $\mathrm{TiC}$ and $\mathrm{TiO}$ structures. ${ }^{[11,12]}$ 
Table 1 shows a comparison of our calculated results for $\mathrm{TiC}_{\mathrm{x}}$ and $\mathrm{TiO}$ with some theoretical and experimental results available in the literature. The calculated lattice parameters are in excellent agreement with results of other studies, with our results deviating less than $1.5 \%$ from experiments. However, our calculations overestimate the cohesive energy of $\mathrm{TiC}$, and probably $\mathrm{TiO}$, relative to experiments by more than $20 \%$, which can be attributed to systematic errors in the description of the exchange-correlation term and/or to an improper accounting of the final states of isolated atoms ${ }^{[11]}$. The elastic constants and moduli for stoichiometric TiC are also in very good agreement with results from other simulations and experiments. Note also, that the lattice parameter, cohesive energy and elastic moduli decrease with the introduction of vacancies in the carbon sublattice, which is confirmed experimentally.

Table 2 shows the equilibrium lattice parameter and cohesive energy for $\mathrm{TiC}_{\mathrm{x}} \mathrm{O}_{\mathrm{y}}$ with different carbon and oxygen content. There is a good agreement between the calculated lattice parameters and experimental ones, with calculations deviating less than $1 \%$. Note, that our calculations are for stoichiometric bulk material, whereas our measurements are for overstoichiometric thin film, with thickness 1-3 $\mu \mathrm{m}$, which is probably why the calculations are in better agreement with experimental data for stoichiometric bulk material. The lattice parameter and cohesive energy were found to decrease with the increase of oxygen content by substitution of carbon by oxygen atoms in the lattice. The decrease of cohesive energy (binding energy of atoms for crystals) is related with the increasing metallic character of the compounds, due to the weakening of covalent part of bonding with respect to the metallic one, as discussed above. The insertion of an oxygen atom as an interstitial in the $\mathrm{TiC}$ structure is accompanied by a strong increase of the lattice parameter, characteristic of the presence of impurity interstitials in a lattice.

It is well known that elastic moduli are correlated with certain material properties, such has hardness, strength, ductibility, etc. The Bulk modulus is related with average atomic bond strength, which is strongly correlated with cohesive energy, whereas the shear and Young's modulus are 
associated with material intrinsic Hardness, with a larger moduli corresponding generally to harder materials. Pettifor ${ }^{[13]}$ suggested that Cauchy pressure can be used to describe the metallic character of atomic bonding (ductibility/brittleness), being positive for ductile materials and negative for brittle semiconductors. Table 3 lists the calculated elastic constants and elastic moduli of $\mathrm{TiC}_{\mathrm{x}} \mathrm{O}_{\mathrm{y}}$ structures. The increase of oxygen content leads to a decrease of $B$ and elastic constants $C_{12}$ and $C_{44}$, while the shear, Young's modulus and $C_{11}$ elastic constant exhibit a complex trend. The discrepancy between calculated and measured Young's modulus, is probably due to the intrinsic porosity of the films, which was not taken in consideration in the calculations. The Cauchy pressure becomes less negative with the introduction of oxygen, becoming positive with introduction of vacancies in the carbon sublattice of $\mathrm{TiC}$ (see table 1) and for high oxygen content, which confirms an increase in the metallic character of the compounds.

\section{Conclusion}

We studied the electronic, structural and mechanical properties of $\mathrm{TiC}_{\mathrm{x}} \mathrm{O}_{\mathrm{y}}$ structures, using an ab initio approach based on DFT and the pseudo potential method. The calculations provide the theoretical lattice parameter, density of states, cohesive energy, elastic constants and moduli as a function of carbon and oxygen content. These results for the lattice parameters are in good agreement with the experiments performed by us and others researchers. The agreement is not so good for the Young's modulus, since calculations did not consider any porosity. Our theoretical results have shown that the lattice parameter, cohesive energy, bulk modulus, $C_{12}$ and $C_{44}$ elastic constants of $\mathrm{TiC}_{\mathrm{x}} \mathrm{O}_{\mathrm{y}=1-\mathrm{x}}$ decrease with increasing oxygen content, whereas Cauchy pressure increases. The shear and Young's modulus and $C_{11}$ elastic constant, do not seem to have a clear trend. 


\section{References}

[1] I. Dahan, A. Admon, N. Frage, J. Sariel, M.P. Dariel, J.J. Moore, Surf. Coat. Technol., 2001, $137,111$.

[2] A. Voevodin, M. Capano, S. Laube, M. Donley, J. Zabinski, Thin Solid Films, 1997, 298, 107.

[3] Y. Suda, H. Kawasaki, K. Doi, S. Hiraishi, Thin Solid Films, 2000, 374, 282.

[4] L.-Y. Kuo, P. Shen, Mat. Sci. and Eng. A, 2000, 276, 99.

[5] D. Chicot, Y. Benarioua, J. Lesage, Thin Solid Films, 2000, 359, 228.

[6] J. Kubarsepp, H. Klaasen, J. Pirso, Wear, 2001, 249, 229.

[7] W. Kohn, L. J. Sham, Phys. Rev A, 1965, 140, 1133.

[8] M. Segall, P. Lindan, M. Probert, C. Pickard, P. Hasnip, S. Clark, M. Payne, J. Phys.: Condens. Matter, 2002, 14, 2717.

[9] J. P. Perdew, K. Burke, M. Ernzerhof, Phys. Rev. Lett., 1996, 77, 3865.

[10] J. H. Monkhorst, J. Pack, Phys. Rev. B, 1976, 13, 5188.

[11] A. Arya, E. A. Carter, J. Chem. Phys., 2003, 118, 8982.

[12] R. Ahuja, O. Eriksson, J. Wills, B. Johansson, Phys. Rev. B, 1996, 53, 3072.

[13] D. G. Pettifor, Mater. Sci. Technol., 1992, 8, 345.

[14] W. Wolf, R. Podloucky, T. Antretter, F. Fischer, Phil. Mag. B, 1999, 79, 839.

[15] P. Jochym, K. Parlinski, M. Sternik, Eur. Phys. J. B, 1999, 10, 9.

[16] A. Dunand, H. D. Flack, K. Yvon, Phys. Rev. B, 1985, 31, 2299.

[17] “Transition Metal Carbides and Nitrides”, L. E. Toth, Academic press, New York 1971.

[18] D. Rowcliffe, G. E. Hollox, J. Mater. Sci., 1971, 6, 1270.

[19] N. A. Ivanov, L. P. Andreeva, P. V. Gel'd, Powder Metall. Met. Ceram., 1978, 17, 613.

[20] Y. Zainulin, S. Alyamovsky, G. Shveikin, J. Phys. Chem. Solids, 1978, 39, 29.

[21] S. Bartkowski, M. Neumann, E. Kurmaev, V. Fedorenko, S. Shamin, V. Cherkashenko, S. Nemnonov, A. Winiarski, D. C. Rubie, Phys. Rev. B, 1997, 56, 10656. 


\section{Figure captions}

Fig. 1: Calculated density of states (DOS) for TiC: Total DOS (solid line), C 2s-partial DOS (dashed), C 2p-partial DOS (dotted), Ti 3d-partial DOS (dash-dotted). The Fermi energy $\left(\varepsilon_{\mathrm{F}}\right)$ is set at zero energy and is marked by dotted vertical line.

Fig. 2: Calculated density of states (DOS) for TiO: Total DOS (solid line), O 2s-partial DOS (dashed), O 2p-partial DOS (dotted), Ti 3d-partial DOS (dash-dotted). The Fermi energy $\left(\varepsilon_{\mathrm{F}}\right)$ is set at zero energy and is marked by dotted vertical line. 
Table 1 Results from calculations (Calc) of lattice parameter $\left(a_{0}\right)$, Cohesive energy $\left(E_{c o h}\right)$, bulk modulus $(B)$, Shear modulus $(G)$, Young's modulus $(E)$ and elastic constants $\left(C_{11}, C_{12}, C_{44}\right)$ of $\mathrm{TiC}_{\mathrm{x}}$ and $\mathrm{TiO}$ structures compared with other calculated and experimental (Expt) data.

\begin{tabular}{|c|c|c|c|c|c|c|c|c|c|}
\hline$\overline{\text { System }}$ & Method & $a_{0}(\AA)$ & $\overline{E_{\text {coh }}(\mathrm{ev})}$ & $B(\mathrm{GPa})$ & $G(\mathrm{GPa})$ & $E(\mathrm{GPa})$ & $C_{11}(\mathrm{GPa})$ & $C_{12}(\mathrm{GPa})$ & $C_{44}(\mathrm{GPa})$ \\
\hline & This work (Calc.) & 4.341 & 8.85 & 244.0 & 185.5 & 444.0 & 491.3 & 120.3 & 189.2 \\
\hline & LDA-FLAPW ${ }^{\mathrm{a})}$ & 4.316 & & 286 & 201 & 488 & 610 & 124 & 173 \\
\hline \multirow[t]{3}{*}{ TIC } & GGA-PWPP ${ }^{b)}$ & 4.345 & & 246 & 198 & 469 & 521 & 109 & 193 \\
\hline & GGA-PWPP $^{c)}$ & 4.348 & 7.74 & 247 & & & & & \\
\hline & Expt & $4.329^{\mathrm{d})}$ & $7.10^{\mathrm{e})}$ & $242^{\mathrm{e})}$ & & & & & \\
\hline $\mathrm{TiC}_{0.91}$ & $\mathrm{Expt}^{\mathrm{f})}$ & & & 242 & 189 & 450 & 514 & 106 & 179 \\
\hline $\mathrm{TiC}_{0.84}$ & $\operatorname{Expt}^{\mathrm{g})}$ & & & 233 & 164 & 400 & & & \\
\hline $\mathrm{TiC}_{0.81}$ & $\operatorname{Expt}^{\mathrm{h})}$ & 4.331 & & & & & & & \\
\hline $\mathrm{TiC}_{0.75}$ & This work (Calc.) & 4.312 & 8.54 & 213.0 & 144.3 & 353.2 & 405.4 & 117.1 & 95.4 \\
\hline $\mathrm{TiC}_{0.72}$ & $\operatorname{Expt}^{\mathrm{h})}$ & 4.328 & & & & & & & \\
\hline $\mathrm{TiC}_{0.6}$ & $\operatorname{Expt}^{\mathrm{h})}$ & 4.314 & & & & & & & \\
\hline \multirow{3}{*}{$\mathrm{TiO}$} & This work (Calc.) & 4.264 & 8.40 & 220.0 & 222.5 & 499.2 & 517.2 & 71.3 & 36.2 \\
\hline & LDA-FPLMTO $^{\mathrm{i})}$ & 4.268 & & 280 & 202 & 489 & 693 & 73 & 130 \\
\hline & $\operatorname{Expt}^{\mathrm{j})}$ & 4.20 & & & & & & & \\
\hline
\end{tabular}

${ }^{\text {a) }}$ Reference 14 .

b) Reference 15 .

${ }^{c)}$ Reference 12 .

d) Reference 16.

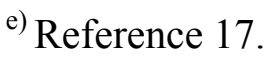

f) Reference 18 .

g) Reference 14.

h) Reference 20 .

i) Reference 13.

${ }^{j)}$ Reference 21 . 
Table 2 Calculated and experimental lattice parameter $\left(a_{0}\right)$, Cohesive energy $\left(E_{c o h}\right)$ of $\mathrm{TiC}_{\mathrm{x}} \mathrm{O}_{\mathrm{y}}$ structures.

\begin{tabular}{l|ll}
\hline System & $a_{0}(\AA)$ & $E_{\text {coh }}(\mathrm{eV})$ \\
\hline Calculations & 4.341 & 8.85 \\
$\mathrm{TiC}$ & 4.313 & 8.78 \\
$\mathrm{TiC}_{0.75} \mathrm{O}_{0.25}$ & 4.295 & 8.66 \\
$\mathrm{TiC}_{0.5} \mathrm{O}_{0.5}$ & 4.284 & 8.52 \\
$\mathrm{TiC}_{0.25} \mathrm{O}_{0.75}$ & 4.264 & 8.40 \\
$\mathrm{TiO}$ & 4.510 & 8.22 \\
$\mathrm{TiC}\left(\mathrm{O}_{\text {interstitial }}\right)$ & 4.38 & \\
\hline Experimental & 4.35 & \\
$\mathrm{TiC}_{0.74} \mathrm{O}_{0.23}{ }^{\text {a) }}$ & 4.315 & \\
$\mathrm{TiC}_{0.56} \mathrm{O}_{0.46}{ }^{\text {a) }}$ & 4.299 & \\
$\mathrm{TiC}_{0.28} \mathrm{O}_{0.75}{ }^{\text {a) }}$ & 4.256 & \\
$\mathrm{TiC}_{0.87} \mathrm{O}_{0.11}$ b) & 4.321 & \\
$\mathrm{TiC}_{0.73} \mathrm{O}_{0.27}{ }^{\text {b) }}$ & 4.317 & \\
$\mathrm{TiC}_{0.63} \mathrm{O}_{0.39}$ b) & 4.306 & \\
$\mathrm{TiC}_{0.32} \mathrm{O}_{0.84}$ & \\
$\mathrm{TiC}_{0.39} \mathrm{O}_{0.65}$ & \\
\hline${ }_{1.57} \mathrm{O}_{0.16}$ &
\end{tabular}

a) Reference 19 .

b) Reference 20 . 
Table 3 Calculated elastic moduli $(B, G$ and $E)$, elastic constants $\left(C_{11}, C_{12}\right.$ and $\left.C_{44}\right)$, Cauchy pressure $\left(C_{12}-C_{44}\right)$, and experimental Young's modulus $(E)$ of $\mathrm{TiC}_{\mathrm{x}} \mathrm{O}_{\mathrm{y}}$ structures.

\begin{tabular}{|c|c|c|c|c|c|c|c|}
\hline System & $B(\mathrm{GPa})$ & $E(\mathrm{GPa})$ & $G(\mathrm{GPa})$ & $C_{11}(\mathrm{GPa})$ & $C_{12}(\mathrm{GPa})$ & $C_{44}(\mathrm{GPa})$ & $C_{12}-C_{44}(\mathrm{GPa})$ \\
\hline \multicolumn{8}{|c|}{ Calculations } \\
\hline $\mathrm{TiC}$ & 244.0 & 444.0 & 185.5 & 491.3 & 120.3 & 189.2 & -68.9 \\
\hline $\mathrm{TiC}_{0.75} \mathrm{O}_{0.25}$ & 243.2 & 464.8 & 196.7 & 505.4 & 111.9 & 146.9 & -34.9 \\
\hline $\mathrm{TiC}_{0.5} \mathrm{O}_{0.5}$ & 234.8 & 476.2 & 204.9 & 508.3 & 105.3 & 127.7 & -22.4 \\
\hline $\mathrm{TiC}_{0.25} \mathrm{O}_{0.75}$ & 225.4 & 442.7 & 188.8 & 476.3 & 100.3 & 36.0 & 64.3 \\
\hline $\mathrm{TiO}$ & 220.0 & 499.2 & 222.5 & 517.2 & 71.3 & 36.2 & 35.1 \\
\hline \multicolumn{8}{|c|}{ Experimental } \\
\hline $\mathrm{TiC}_{0.32} \mathrm{O}_{0.84}$ & & 308 & & & & & \\
\hline $\mathrm{TiC}_{0.39} \mathrm{O}_{0.65}$ & & 272 & & & & & \\
\hline $\mathrm{TiC}_{1.57} \mathrm{O}_{0.16}$ & & 327 & & & & & \\
\hline $\mathrm{TiC}_{1.29} \mathrm{O}_{0.83}$ & & 269 & & & & & \\
\hline
\end{tabular}




\section{Text for table of contents}

In this work we present the first theoretical study of structural, electronic and mechanical properties

of $\mathrm{TiC}_{\mathrm{x}} \mathrm{O}_{\mathrm{y}}$, using first principles DFT calculations. Our results for lattice parameters and elastic moduli are generally in good agreement with experiments and other theoretical results. 